International Journal of Engineering \& Technology, $7(3.2)(2018) 392-397$
International Journal of Engineering \& Technology
Website $:$ www.sciencepubco.com/index.php/IJET
Research paper

\title{
Modeling of the Management System for the Small Hotels Construction
}

\author{
Vira Shchepak $^{1 *}$, Natalia Senenko ${ }^{2}$, Inna Senenko ${ }^{3}$ \\ ${ }^{1}$ Poltava National Technical Yuri Kondratyuk University, Ukraine \\ ${ }^{2}$ Poltava National Technical Yuri Kondratyuk University, Ukraine \\ ${ }^{3}$ Kyiv National University Of Trade And Economics, Ukraine \\ *Corresponding Author E-Mail:Kanameshch@Gmail.Com
}

\begin{abstract}
The aim of the work was to investigate the aspects of construction, simulate the management system for the construction of small hotels with the development of the graph model, determine the main characteristics of the system components and perform their evaluation using the integrated assessment technique.

A systematic approach was used in the process of preparing the publication.

The study has determined that the construction of hotels is formed under the influence of a significant number of different factors of the external and internal environment and is a complex process. It is proposed to consider the construction of small hotels in conjunction with the financing, design, development of recreational areas and profitability of the future hotel business.

The construction management system is also complex and complicated. For the effective functioning of such a system, the integration of its components on the basis of modeling was carried out. For this purpose, graph theory has been used and a graph-model of the control system has been developed. This approach made it possible to simplify the management system for the construction of small hotels and to distinguish two main subsystems: engineering-construction and economics. The first subsystem includes building objects and recreational areas, the second - investor-customers.

The components and functions of the model have been described. The basic characteristics of subsystems and their interrelations were singled out. Then an example of an assessment of the main characteristics of the engineering and construction subsystem using the integrated assessment technique was given.

As a result, the most effective variant of the formation of the engineering and construction component of the management system for the construction of small hotels has been determined.

Prospects for further research are an in-depth study of the interrelationships between the components of the management system for construction of small hotels and formation of the development direction for this system.
\end{abstract}

Keywords: building management system, evaluation; modeling.

\section{Introduction}

Construction is one of the main branches that affect the development of the production industry, raising labor productivity, improving the material well-being and cultural standard of the population life.

Recently, the changes in construction industry that caused a number of difficulties in the management and organization of construction have occurred. This led to a constant reduction in the scales and volumes of construction, an increase in the requirements for the quality of the constructed facilities, the need to increase the share of capital investments for reconstruction and technical re-equipment, an increase in the requirements for quality characteristics of the facilities under construction.

Construction is a complex organizational and technological process in which enterprises and divisions of various industries can be involved.

The complexity of the organization of construction lies in the diversity of the organizational and economic forms, the methods of production process, a large number of participants who have dif- ferent functional purposes and tasks, the essential dependence of the construction process on natural environmental conditions. The global market of construction industry has a tendency to expand its segments. One of such segments is the construction of small hotels. The trend of increased demand for hotel services has led to the creation of a huge number of hotel chains. These systems occupy most of the hotel capacity, have great financial resources and consist of small hotels.

Construction management, which is aimed at solving of local tasks, which cover certain types of work, does not ensure the organizational and technological unity of construction.

Therefore, such management does not have a proper impact on the efficiency of construction industry and the acceleration of the achievement of ultimate goals.

Thereby, it is necessary to study modern aspects of construction management with the development of an appropriate model of the management system, as well as methods for evaluating its components. 


\section{Main Body}

In scientific studies, the construction industry is considered as a loosely related system. The identity, uniqueness and isolation of the elements are preserved in it and therefore it can generate diversity. The system can potentially save more options and new solutions than in the case of a tightly related system. A greater degree of freedom in a loosely related system means that its components face different interaction problems, and thus contribute to the diversity of the development of the construction industry system and the use of innovations [1].

Investors, customers, designers, contractors, specialized construction organizations are directly involved in the process of building production. Also, manufacturing plants of technological equipment, construction machinery and materials participate in the creation of construction objects.

Since a large number of participants are involved, it can be argued that the construction process is formed under the direct influence of a significant number of organizational factors. In addition, business factors that characterize the profitability of construction objects during their operation also affect the construction process The interest of investor-customers in financing of construction depends on the profit that can be obtained from the invested capital.

Evaluation of the success factors of construction projects shows that productivity in the construction industry is the most important among them $[2,3]$. Motivational processes of construction projects are also important for their success $[4,5]$. Analysis of the specifics of the work and qualification of project agents showed that the effectiveness of construction projects depends on their successful work [6]. Also the importance of motivational factors of employment for disparate occupational groups in the construction sector is emphasized [7]. At the same time, construction managers should pay more attention to employee motivation, which positively affects the success of the project [8]. Methods for modeling of structural equations are used to determine such an effect [9]. It is also possible to use motivation models that are based on the expectations theory.

Modern hotels should be objects of high quality services for accommodation, decoration, as well as meeting the needs of nowadays travelers [10]. Hotels with eco-friendly stylish rooms and local art features used are most in demand [11].

To meet the increased demand for such hotels and ensure such conditions for tourists, there is a need to build new small hotels. Furthermore, the influence of the architectural heritage of buildings is taking into account [12].

According to the research, it was determined that many factors affect the choice of hotels location. These are such factors as accessibility of communication, transport infrastructure, accessibility of recreational areas and tourist assets [13].

The construction of hotel business facilities requires taking into account the methodological aspects of strategic financial risk management [14].

Financial risks are considered as a multifaceted concept, depending on many factors of the external and internal environment of small hotels. They can arise both in the process of investing to the construction projects of small hotels, their construction, and during the development of the hotel business. Successful risk management provides an opportunity to attract investment, both in construction and in the hotel business. Two major strategies for the development of the hotel business are being considered. The strategy of geographic expansion, which is based on an active access to new markets through the launch of a larger number of standard hotels is assigned to the first. Oriented geographic strategy, which implies lower growth rates, as growth is achieved by means of increasing the number of hotels with unique and firstclass services is attributed to the second. At the same time, special attention should be paid to the risks associated with the financing of investment projects and the valuation of their costs, as well as the profit forecast for a successful revenue management system in hotels [14].

Thus, management in construction is diverse and cannot be fully realized in a single construction organization.

This necessitates the transition to the formation of a management system based on integration processes, which unites organizations that directly or indirectly affect the efficiency of construction. Since the objects of construction are too diverse, it is necessary to take into account their specificity of erection, functioning and their competitiveness in forming a building management system.

Recently, the increased demand for the construction of small hotels is available. So the development of new approaches to building management system is required [15].

The formation of a management system for the construction of small hotels has certain characteristics, since the construction of such buildings must take into account their location relative to recreational areas, the possibility of using these resources for rest of tourists, as well as profit from the hotel business.

The construction of new small hotels or the reconstruction of old buildings should take into account modern financing conditions. Those projects are invested which will be profitable in the future. Therefore, the construction of small hotels should be considered together with financing, design, development of recreational areas and profitability of the future hotel business.

The authors proposed to divide this process into five main functions. The first function is to identify an investor who is interested in the development of the hotel business and has the desire to invest financial resources in the construction of small hotels of high demand in the hotel services market.

The second function is aimed at creating a construction project, which should take into account the influence of various factors of external and internal environment. The main factors of the external environment are the characteristics of the adjacent territories, including recreational ones, as they can be used for tourists rest. The main factors of the internal environment are the features of small hotels lay-out, interior and exterior decoration, use of environmentally friendly designs and materials. This function also includes the direct construction of small hotels, as a result of which the erection of buildings and landscaping of adjacent territories are carried out.

The third function is characterized by the development of recreational areas, as objects of leisure travelers.

The organization of an effective hotel business with the use of cooperation with companies that form the brands of hospitality services is assigned to the fourth function.

The formation of innovative brands, which as a result of the development are represented by tourist routes, maps, guidebooks, are referred to the fifth function.

All listed functions are in interrelation and interaction with each other. It is necessary to coordinate the performance of these functions. Therefore, to ensure their effective implementation, it is proposed to form a management system for the construction of small hotels, the functioning of which will be aimed at the effective performance of these functions.

These functions form the process of functioning of the construction management system.

Thus, the management system for the construction of small hotels is characterized by a multifactor formation, which determines the need to use modeling.

The aggregate of logical relations was used in creating a model of the management system for the construction of small hotels. This mapping combines the groups of elements of the control system under study into similar groups of model elements. In other words, the model is a conditional image of a control system designed to simplify its study. The study of such a model gives new knowledge about this management system.

By definition, the model is abstract. It identifies the most significant factors, determines the regularities of the functioning of the control system being studied. Moreover, it is abstracted from other factors that though having very little effect can determine the behavior of the model in the aggregate. 
It is assumed that all factors that are not explicitly taken into account in the model have an insignificant effect on the control system in the investigation aspect. The composition of the model factors taken into account and its structure can be improved on the basis of knowledge gained as a result of deepening the study of the management system.

Long-term world experience has proved that models can be a powerful tool for scientific analysis and forecasting, obtaining results-conclusions that are adequate to the studying object [16].

All the interrelationships of the management system for the construction of small hotels can be quantified in forming a model These allow obtaining objective data on the state of functioning of this management system.

Interpretation of simulation results is aimed at moving from information obtained on the basis of model research to describing the components and their interrelationships in the management system for the construction of small hotels

Decisions regarding the conditions in which the management system will function most effectively are taken on the basis of analysis of the results of modeling.

The model of the management system for the construction of small hotels is considered by the authors as a set of enlarged components, fundamentally necessary for the existence and functioning of the investigated system.

The unity of the system elements, the connections and interactions between them form the integrity of the system, and the components - the structure.

The authors proposed two subsystems: engineering-construction and economic - are the enlarged components of this system. In this case, the objects that correspond to each function are components of the system.

Such components as general contracting organizations, construction industry enterprises, logistics organizations, construction sites and recreational areas are belong to the first.

Investors and partner companies on innovative brands form the second subsystem.

The use of innovative brands in the hotel business provides a certain part of the profit. Therefore, cooperation of investors with companies that form the industry of hospitality and tourism is necessary. They use different brands, create maps of local different routes for hotel guests [17].

For effective functioning of the management system of the small hotels construction, managers able to ensure optimal interaction of the considered system components are necessary. The management of the components is aimed at organizing the investment and implementation of the construction project within available resources, as well as ensuring the effective functioning of the hotel business in the future.

There are interconnections between subsystems.

So, as a result of the analysis, the components were identified and the interrelationships of the building management system for small hotels were identified by the authors.

On the basis of this approach, a graph-model is formed, as shown in Figure 1.

The presented model has edges (links) and vertices (corresponding subsystems), which are united in a single system $(S)$.

A particular vertex of the graph-model corresponds to each component of the system. The vertex $S_{h}$ corresponds to the construction objects, $S_{r}$ - recreational areas, $S_{g}$ - general contractor organizations, $S_{b}$ - construction industry enterprises, $S_{l}$ - logistics organizations, $S_{c}$ - investors-customers, $S_{k}-$ partner companies, $S_{b r}$ innovative brands.

The edges of the graph-model of the engineering-construction subsystem $\left(S_{r}-S_{h}\right),\left(S_{h}-S_{r}\right),\left(S_{g}-S_{h}\right),\left(S_{l}-S_{h}\right),\left(S_{b}-S_{h}\right)$ characterize the interrelations between the construction objects (small hotels) and general contractor organizations, construction industry enterprises, logistics organizations, recreational areas.

The edge of the graph-model of the economic subsystem $\left(S_{c}-S_{k}\right)$ characterizes the relationship between investor-customers and partner companies; rib $\left(S_{k}-S_{b r}\right)$ - between innovative brands and partner companies.
There are the economic interrelations that are characterized by edges of the graph-model $\left(S_{c}-S_{h}\right),\left(S_{h}-S_{c}\right),\left(S_{r}-S_{b r}\right),\left(S_{b r}-S_{h}\right)$ between subsystems. Together, the vertices and ribs form a structure that graphically represents the model of a small hotel management system.

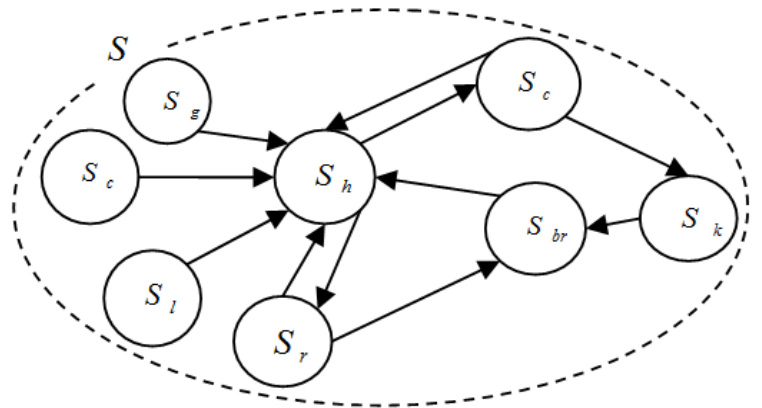

Fig. 1: Graph-model of the management system for the small hotels construction

As a result of the study of model relationships, single links that affect only one component have been identified. On their basis, the integration of the subconstituent systems was carried out.

After such changes, the engineering and construction subsystem is represented by construction objects and recreational areas. Economic one is represented by investors respectively, as shown in Figure 2.

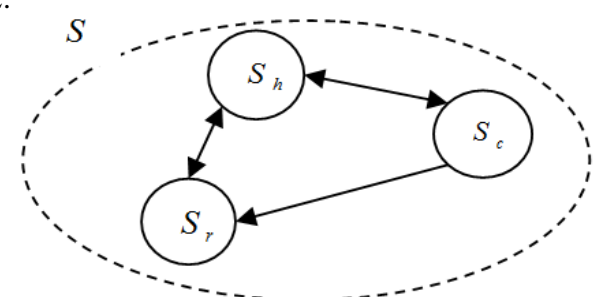

Fig. 2: Graph-model of the management system for the small hotels construction after integration

Description of the graph-model of the management system for the construction of small hotels was proposed to be implemented on the basis of the structural-functional approach [18]. To this end, using the approach methodology, the authors investigated the management system for the small hotels construction and determined:

- primary element of the system $\left(S_{i} \in S\right), i=h, r, c$;

- a list of subsystems and elements based on the structural decomposition method is compiled;

- existing links in the system are defined;

- a plurality of impact on the system (Yo) processes was formed;

- the mechanism for realizing the goals of the system is defined:

$\left(F \times Y_{0} \times G \rightarrow E_{0}\right)$.

- the mechanism of the system functioning is defined:

$\left(Y_{0} \rightarrow E_{0}\right)$

As a result, the overall model of a small hotel management system was obtained. On the basis of this approach, the description of the system $(S)$ of the graph-model has the form:

$S=\left\langle Y_{o}, E_{o}, F, G, R\right\rangle$.

Where $Y_{o}$ - the cost of resources of the management system for the small hotels construction;

$E_{o}$ - efficiency of the management system for the small hotels construction;

$F$ - macrofunction of the system;

$G$ - the system structure;

$R$ - emergence ratio. 
Emergence is availability in the system of properties of integrity (emergent properties), that is, properties that are not characteristic of its elements and which are one of the manifestations of the dialectical principle of the transition of quantity to quality. The emergence of a system is certain qualities of a given system that are not inherent in its elements individually, but arise from the association of these elements into a single, integrated system.

Macro function of the system is a quantitative expression of the main purpose of the system and depends on the cost of consumed resources.

The choice of macro function ensures the achievement of the required economic efficiency of the management system for the small hotels construction.

It is connected with the solution of the tasks facing the system. Only with certain resources $\left(U_{o}\right)$ ensuring efficiency $\left(E_{o}\right)$ of the system is possible. The mathematical expression of a macro function is:

$F: U_{0} \rightarrow E_{0}$

Achieving the main goal of the system is possible when implementing a macro function $(F)$, for which a certain structure of the system $(G)$ and its integrity $(R)$ must correspond:

$$
R: F \rightarrow G
$$

The emergence ratio $(R)$ determines the correspondence between the macrofunction of the system $(F)$ and the structure $(G)$ that it implements. The emergence ratio $(\mathrm{R})$ changes each time the correspondence between the macro function and the structure is violated. The dependence is defined as follows:

$$
G=\left\langle\left\{S_{h}, S_{r}, S_{c}\right\},\left(S_{r}, S_{h}\right),\left(S_{h}, S_{r}\right),\left(S_{h}, S_{c}\right),\left(S_{c}, S_{h}\right),\left(S_{c}, S_{r}\right)\right\rangle .
$$

Where $\left\{S_{h}, S_{n} S_{c}\right\}$ - vertices of the graph-model;

$h, r, c$ - indices, characterizing the components of the system, construction objects - small hotels, recreational areas, investors respectively;

$\left(S_{r}-S_{h}\right),\left(S_{h}-S_{r}\right),\left(S_{h}-S_{c}\right),\left(S_{c}-S_{h}\right),\left(S_{c}-S_{r}\right)-$ set of connections between the vertices of the graph-model.

The components of the graph-model (Figure 2) are represented by the 8 functions $\left(f_{n}, n=1 \ldots 8\right)$ :

$$
\begin{aligned}
& f_{1}: S_{r} \rightarrow\left\{Y_{c}, P_{c}\right\} . \\
& f_{2}: S_{h} \rightarrow\left\{Y_{h}, M T_{h}, t_{h}, F R_{h}, E_{h}, N_{h}\right\} . \\
& f_{3}: S_{r} \rightarrow\left\{N G_{r}, N A_{r}, H K_{r}, E_{r}\right\} . \\
& f_{4}:\left(S_{r}-S_{h}\right) \rightarrow\left\{L_{r-h}, C H_{r-h}\right\} . \\
& f_{5}:\left(S_{c}-S_{r}\right) \rightarrow\left\{Y_{c-r}\right\} . \\
& f_{6}:\left(S_{h}, S_{r}\right) \rightarrow\left\{R A_{h-r}\right\} . \\
& f_{7}:\left(S_{c}-S_{h}\right) \rightarrow\left\{Y_{c-h}\right\} . \\
& f_{8}:\left(S_{h}-S_{c}\right) \rightarrow\left\{R E V_{h-c}\right\} .
\end{aligned}
$$

The first three functions $\left(f_{1}, f_{2}, f_{3}\right)$ characterize the components of the system, the remaining functions - connections between them. Investors-customers are the main source of financing for the construction of small hotels. They have a certain amount of financial resources $\left(Y_{c}\right)$, which can invest in the construction and development of the hotel business on the assumption of profit $\left(P_{c}\right)$.
The construction objects are characterized by the cost of the construction project $\left(Y_{h}\right)$, the cost of logistics $\left(M T_{h}\right)$, the duration of construction $\left(t_{h}\right)$, financial risks $\left(F R_{h}\right)$, the efficiency of construction of small hotels $\left(E_{h}\right)$ and the payback of construction $\left(N_{h}\right)$.

At the same time, material and technical support is aimed at a network of enterprises of industry and construction industry, transport and energy organizations, design and other institutions. It is aimed at ensuring the small hotels construction with the necessary material and technical resources.

Recreational areas are an essential component in the organization of the hotel business, as they are used to organize recreation for tourists. They are characterized by natural-geographical resources $\left(N G_{r}\right)$, natural-anthropogenic resources $\left(N A_{r}\right)$, historical and cultural resources $\left(H K_{r}\right)$ and the efficiency of recreational territories $\left(E_{r}\right)$.

The relationship between construction objects and recreational areas is characterized by the fourth function $\left(f_{4}\right)$. The location of recreational areas affects the choice of the construction site $\left(L_{r-h}\right)$. The characteristics of these territories are also important in the formation of innovative brands $\left(\mathrm{CH}_{r-h}\right)$ for hotel tourists.

In addition, investments are directed into the development of recreational resources $\left(Y_{c-t}\right)$. This is the fifth function $-f_{5}$.

The use of recreational areas for rest and entertainment $\left.\left(R A_{h-r}\right)\right)$ is characterized by the sixth function $\left(f_{6}\right)$.

The following functions characterize the relationship between investors and the small hotels construction.

This characteristic is the amount of financial resources $\left(Y_{c-h}\right)$ that are invested in construction. This is the seventh function $-f_{7}$. The eighth function $\left(f_{8}\right)$ characterizes the receipt of income from the hotel business $\left(R E V_{h-c}\right)$.

The interaction of the components, as an integral system, ensures their dynamic development. Model of the management system for the construction of small hotels proposed by the authors shows the interdependence of its components and describes the parameters of their interaction.

Therefore, the use of simulation allowed us to identify the most important interrelationships between the components of a construction management system for small hotels and to characterize the dependencies between the parameters of these components.

To formalize the processes of analysis and evaluation of the system, its components, interrelations between them, which are represented by functions in the graph-model, the integral evaluation technique is proposed to use [19].

The basis of such a technique is based on a systematic approach, which takes into account the interaction and interdependence of characteristic features.

This makes it possible to carry out an integral assessment while ensuring its maximum objectivity.

The assessment of the engineering-construction subsystem, which is the main component of the management system for small hotel construction, was completed. At that, 5 variants of its projects were considered. Integral assessment was carried out in several stages. First, a set of characteristics of the engineeringconstruction subsystem was formed. For this purpose, the characteristics of construction and recreational areas were used, which are considered in the developed model (formulas 8, 9). Their quantitative values are shown in Table 1.

Table 1: Quantitative characteristic values the engineering-construction subsystem

\begin{tabular}{|c|c|c|c|c|c|c|c|c|c|c|}
\hline Option & ${ }^{I} Y_{h}$ & ${ }^{I} M T_{h}$ & ${ }^{I} F R_{h}$ & ${ }^{2} t_{h}$ & ${ }^{3} E_{h}$ & ${ }^{2} N_{h}$ & ${ }^{4} N G_{r}$ & ${ }^{4} N A_{r}$ & ${ }^{4} H K_{r}$ & ${ }^{3} E_{r}$ \\
\hline 1 & 1200 & 600 & 240 & 6 & 26 & 48 & 77 & 65 & 44 & 77 \\
\hline 2 & 1500 & 900 & 375 & 9 & 31 & 56 & 45 & 53 & 81 & 71 \\
\hline 3 & 1700 & 969 & 374 & 8 & 27 & 58 & 67 & 72 & 22 & 63 \\
\hline 4 & 1800 & 1008 & 378 & 11 & 28 & 55 & 39 & 82 & 36 & 57 \\
\hline 5 & 2000 & 1320 & 540 & 10 & 35 & 60 & 72 & 54 & 43 & 71 \\
\hline $\max$ & 1200 & 600 & 240 & 6 & 26 & 39 & 53 & 22 & 57 & 48 \\
\hline $\min$ & 1500 & 900 & 540 & 11 & 35 & 77 & 82 & 81 & 77 & 60 \\
\hline
\end{tabular}

Units: ${ }^{1}-$ thousand dollars; ${ }^{2}-$ number of months; ${ }^{3}$ - ${ }^{2}$ ercentages; ${ }^{4}-$ points.

These indicators have different units of measurement. Therefore, it was necessary to convert all the indicators into relative values. 
When determining relative indicators, both minimum and maximum values were used.

The relative values of the $i$-th indices of the $j$-th sign of the engineering-construction subsystem are determined taking into account the minimum or maximum value.

If the minimum value of the characteristic is the best, then use the formula:

$$
\bar{X}_{i j}=\frac{X_{i j}(\min )}{X_{i j}} .
$$

Where, $X_{i j}$ is relative values of characteristics;

$X_{i j}$ - quantitative values of characteristics;

$X_{i j}(\min )$ - minimum value of characteristics;

$i$ - number of the considered variants of the formation of the engineering-constructing subsystem, $i-1,2 \ldots n, n=N=5$; $j$-number of characteristics, $j-1,2 \ldots m, m=10$.

If the maximum value of the characteristic is the best, then use the following formula:

$$
\bar{X}_{i j}=\frac{X_{i j}}{X_{i j}(\max )} \text {. }
$$

Where, $X_{i j}(\max )$ - maximum value of characteristics.

A table of relative values of characteristics $\bar{X}_{i j}$ is formed, Table 2

Table 2: Relative values of characteristics, $\bar{X}_{i j}$

\begin{tabular}{|c|c|c|c|c|c|c|c|c|c|c|}
\hline Option & $Y_{h}$ & $M T_{h}$ & $F R_{h}$ & $t_{h}$ & $E_{h}$ & $N_{h}$ & $N G_{r}$ & $N A_{r}$ & $H K_{r}$ & $E_{r}$ \\
\hline 1 & 1,00 & 1,00 & 0,89 & 0,75 & 0,74 & 1,00 & 0,79 & 0,54 & 1,00 & 1,00 \\
\hline 2 & 0,80 & 0,67 & 1,00 & 0,67 & 0,89 & 0,58 & 0,65 & 1,84 & 0,92 & 0,85 \\
\hline 3 & 0,71 & 0,62 & 1,10 & 0,75 & 0,77 & 0,87 & 0,88 & 0,50 & 0,82 & 0,82 \\
\hline 4 & 0,67 & 0,60 & 0,99 & 1,00 & 0,80 & 0,51 & 1,00 & 0,82 & 0,74 & 0,87 \\
\hline 5 & 0,60 & 0,45 & 0,69 & 0,55 & 1,00 & 0,94 & 0,66 & 0,98 & 0,92 & 0,80 \\
\hline$\sum_{i=1}^{n} \bar{X}_{i j}$ & 3,77 & 3,34 & 4,68 & 3,71 & 4,20 & 3,90 & 3,98 & 4,68 & 4,40 & 4,34 \\
\hline
\end{tabular}

Their assessment is based on the obtained relative values of the indicators. For this purpose, it is expedient to use the method of determination of entropy.

By this method, the sum of each column is counted $\sum_{i=1}^{n} \bar{X}_{i j}$. Then, the share of each indicator in the total amount was determined:

$Q_{i j}=\frac{\bar{X}_{i j}}{\sum_{i=l}^{n} \bar{X}_{i j}}$

Where, $Q_{i j}$ - share of the $i$-th indicator in the total sum;

$\sum_{i=1}^{n} \bar{X}_{i j}$ - the sum of the values of the $i$-th indicators.

The results of calculations $\left(Q_{i j}\right)$ are summarized in the table 3 .

Then the entropy value of the $j$-th attribute for each column of the table was determined by the formula:

$$
E_{j}=-\frac{1}{\ln N} \sum_{i=l}^{n}\left(Q_{i j} \times \ln Q_{i j}\right) \text {. }
$$

Where, $E_{j}$ - entropy of the $j$-th sign.

10 values of such entropies have been obtained.
Table 3: Values of characteristics, $Q_{i j}$

\begin{tabular}{|c|c|c|c|c|c|c|c|c|c|c|}
\hline Option & $Y_{h}$ & $M T_{h}$ & $F R_{h}$ & $t_{h}$ & $E_{h}$ & $N_{h}$ & $N G_{r}$ & $N A_{r}$ & $H K_{r}$ & $E_{r}$ \\
\hline 1 & 0,27 & 0,30 & 0,19 & 0,20 & 0,18 & 0,26 & 0,20 & 0,12 & 0,23 & 0,23 \\
\hline 2 & 0,21 & 0,20 & 0,21 & 0,18 & 0,21 & 0,15 & 0,16 & 0,39 & 0,21 & 0,20 \\
\hline 3 & 0,19 & 0,19 & 0,24 & 0,20 & 0,18 & 0,22 & 0,22 & 0,11 & 0,19 & 0,19 \\
\hline 4 & 0,18 & 0,18 & 0,21 & 0,27 & 0,19 & 0,13 & 0,25 & 0,17 & 0,17 & 0,20 \\
\hline 5 & 0,16 & 0,14 & 0,15 & 0,15 & 0,24 & 0,24 & 0,17 & 0,21 & 0,21 & 0,18 \\
\hline
\end{tabular}

The objective significance of the $j$-th characteristic is determined by the formula:

$$
d_{j}=1-E_{j}
$$

Where, $d_{j}$ - objective significance of the $j$-th characteristic.

The adduced objective significance of the $j$-th sign is determined by the formula:

$$
\bar{d}_{j}=\frac{d_{j}}{\sum_{j=1}^{m} d_{j}} .
$$

$\bar{d}_{j}-$ the adduced objective significance of the $j$-th sign.

At the second stage, the significance of the influence of subjective signs is determined. There are 10 such signs for the evaluation of the engineering-construction subsystem. In this case it is necessary to determine the advantages of one characteristic over another by the expert method.

They are compared in pairs for this purpose. The corresponding matrix is formed, where the columns and lines are signs, and their characteristics are the indicators, Table 4.

Table 4: Matrix of pairwise comparisons of signs of influence on the state of the engineering-construction subsystem

\begin{tabular}{|c|c|c|c|c|c|c|c|c|c|c|c|}
\hline$J$ & $Y_{h}$ & $M T_{h}$ & $F R_{h}$ & $t_{h}$ & $E_{h}$ & $N_{h}$ & $N G_{r}$ & $N A_{r}$ & $H K_{r}$ & $E_{r}$ & $\sum$ \\
\hline$Y_{h}$ & - & 2 & 2 & 3 & 2 & 2 & 2 & 2 & 2 & 2 & 19 \\
\hline$M T_{h}$ & 2 & - & 2 & 3 & 2 & 3 & 3 & 3 & 2 & 2 & 22 \\
\hline$F R_{h}$ & 2 & 2 & - & 3 & 2 & 1 & 1 & 1 & 1 & 1 & 14 \\
\hline$t_{h}$ & 1 & 1 & 1 & & 1 & 1 & 1 & 1 & & 1 & 8 \\
\hline$E_{h}$ & 2 & 2 & 2 & 2 & - & 2 & 2 & 2 & 2 & 2 & 18 \\
\hline$N_{h}$ & 1 & 1 & 1 & 1 & 1 & - & 2 & 2 & 2 & 2 & 13 \\
\hline$N G_{r}$ & 1 & 1 & 1 & 1 & 1 & 1 & - & 2 & 2 & 2 & 12 \\
\hline$N A_{r}$ & 1 & 1 & 1 & 1 & 1 & 1 & 1 & - & 2 & 2 & 11 \\
\hline$H K_{r}$ & 2 & 2 & 2 & 1 & 1 & 2 & 2 & 2 & - & 2 & 16 \\
\hline$E_{r}$ & 2 & 2 & 2 & 2 & 2 & 2 & 2 & 2 & 2 & - & 18 \\
\hline$\sum$ & 14 & 14 & 14 & 17 & 13 & 15 & 16 & 17 & 15 & 16 & 151 \\
\hline
\end{tabular}

When the subjective significance of this indicator is greater, then the figure 3 is written to the corresponding cell of the matrix, if less -1 , if they are equal -2 .

In this case, the number of indicators $j$ equals $m$, respectively $m=10$.

This significance has a subjective characteristic, since the evaluation is carried out by an expert method.

On the basis of the obtained objective and subjective significances, the generalized significance $q_{j}$ and their the adduced value $\bar{q}_{j}$ are determined, respectively, by the formulas:

$q_{j}=\frac{\bar{g}_{j} \times \bar{d}_{j}}{\bar{g}_{j}+\bar{d}_{j}}$

Where, $q_{j}$ - generalized significance of $j$-th sign.

$\bar{q}_{j}=\frac{q_{j}}{\sum_{j=l}^{m} q_{j}}$.

Where, $\bar{q}_{j}$ - the adduced value of $j$-th sign 
According to the results of the calculations, the entropy table and the significance of the characteristics was formed, Table 5.

Table 5: The values of the entropy and significance of characteristics

\begin{tabular}{|c|c|c|c|c|c|c|c|c|c|c|}
\hline Option & $Y_{h}$ & $M T_{h}$ & $F R_{h}$ & $t_{h}$ & $E_{h}$ & $N_{h}$ & $N G_{r}$ & $N A_{r}$ & $H K_{r}$ & $E_{r}$ \\
\hline$E_{j}$ & 0,90 & 0,88 & 0,99 & 0,89 & 0,94 & 0,95 & 0,94 & 0,90 & 0,94 & 0,91 \\
\hline$d_{j}$ & 0,10 & 0,12 & 0,01 & 0,11 & 0,06 & 0,05 & 0,06 & 0,10 & 0,06 & 0,09 \\
\hline $\bar{d}_{j}$ & 0,14 & 0,16 & 0,01 & 0,14 & 0,08 & 0,07 & 0,08 & 0,13 & 0,08 & 0,11 \\
\hline $\bar{g}_{j}$ & 0,09 & 0,09 & 0,09 & 0,11 & 0,09 & 0,10 & 0,11 & 0,11 & 0,10 & 0,11 \\
\hline$q_{j}$ & 0,06 & 0,06 & 0,01 & 0,06 & 0,04 & 0,04 & 0,05 & 0,06 & 0,04 & 0,05 \\
\hline $\bar{q}_{j}$ & 0,12 & 0,12 & 0,02 & 0,13 & 0,09 & 0,09 & 0,10 & 0,13 & 0,09 & 0,11 \\
\hline
\end{tabular}

At the final stage, the integral estimator is calculated by the formula:

$$
L_{i}=\sum_{j=1}^{m}\left(\bar{X}_{i j} \times \bar{q}_{j}\right)
$$

Where, $L_{i}-$ the integral estimator.

It was determined in assessing the construction subsystem that the most effective option for construction is the second version of the project. Based on the results of the calculations, the integral indicators table is formed, Table 6.

Table 6: Integral index on the options for the formation of the engineering-construction subsystem

\begin{tabular}{|c|c|}
\hline Option & Value \\
\hline 1 & 0,864 \\
\hline 2 & 0,893 \\
\hline 3 & 0,743 \\
\hline 4 & 0,787 \\
\hline 5 & 0,748 \\
\hline
\end{tabular}

The second option is the most effective. It has the largest integral index 0,893 . The third option with the indicator 0,743 is proved to be the worst one. This means that when considering the possibility of construction, it is necessary to choose the second option of the project.

Therefore, the obtained values of integral indicators characterize the effectiveness of the formation of the engineering-construction subsystem according to the options of the projects. The bigger the indicator is, the more efficient the engineering-construction subsystem functions.

\section{Conclusions}

- As a result of graph-model modeling using studies of the management system for the construction of small hotels was formed. A description of the model and its functions is made. This allowed us to identify the main components of the management system for the construction of small hotels, as well as the most important interrelations between them. The main components are engineering-construction and economic subsystems.

- An engineering-construction subsystem was assessed, which consists of construction and recreational areas. For evaluation, the integrated assessment methodology was used. This technique enables taking into account the objective and subjective characteristics of the components.

- The obtained results of the assessment made it possible to determine the option of the most effective formation of the engineering-construction component of the management system for the construction of small hotels.

- Prospects for further research are an in-depth study of the interrelationships between the components of the manage- ment system for the construction of small hotels and the shaping of the direction of development of this system.

\section{References}

[1] Dubois A \& Gadde LE, The construction industry as a loosely coupled system: implications for productivity and innovation, Construction Management and Economics, No. 20 (7), 2002, pp. 621631, doi.org/10.1080/01446190210163543

[2] Gudiene N, Banaitis A \& Banaitiene N, Evaluation of critical success factors for construction projects â an empirical study in Lithuania, International Journal of Strategic Property Management, No. 17 (1), 2013, pp. 21-31, doi.org/10.3846/1648715X.2013.787128

[3] Horta IM, Camanho AS, Johnes J \& Johnes G, Performance trends in the construction industry worldwide: an overview of the turn of the century, Journal of Productivity Analysis, No. 39 (1), 2013, pp. 89-99, doi.org/10.1007/s11123-012-0276-0

[4] Dwivedula R \& Bredillet CN, Profiling work motivation of project workers, International Journal of Project Management, No. 28 (2), 2010, pp. 158-165, doi.org/10.1016/j.ijproman.2009.09.001

[5] Rose T \& Manley K, Motivation toward financial incentive goals on construction projects, Journal of Business Research, No. 64 (7), 2011, pp. 765-773, doi.org/10.1016/j.jbusres.2010.07.003

[6] Xiong L \& Hu N, The Application of Project Agent Construction System Based on the Economic Housing Construction, Seventh International Conference on Measuring Technology and Mechatronics Automation 13-14 June 2015, Nanchang, China, 2015, pp. 1134 1137, doi.10.1109/ICMTMA.2015.276

[7] Dainty ARJ \& Asad S. (2005), Job Motivational Factors for Disparate Occupational Groups within the UK Construction Sector: a Comparative Analysis, Journal of Construction Research, No. 6 (2), pp. 223-236, doi.org/10.1142/S1609945105000341

[8] Chiang CF \& Jang S, (2008) 'An expectancy theory model for hotel employee motivation', International Journal of Hospitality Management, No. $27 \quad$ (2), 2008, pp. 313-322, doi.org/10.1016/j.ijhm.2007.07.017

[9] Musa MM, Amirudin R, Sofield T \& Musa MA, Influence of external factors on the success of public housing projects in developing countries, Construction Economics and Building, No. 154, 2015, pp. 30-44, doi.org/10.5130/AJCEB.v15i4.4514

[10] Dejan ŽĐ \& Marko J (2015), Modern distribution and development of hotel industry in the world, Ekonomika, Vol. 61, No. 3, pp. 99110, doi:10.5937/ekonomika1503099D

[11] Anil B \& Mohammad N, Innovation in hospitality and tourism industries, Journal of Hospitality and Tourism Technology, Vol. 6 , Issue 3, 2015, doi.org/10.1108/JHTT-08-2015-0033

[12] Chotewit P \& Prapatpong U, Changes and Impacts of Heritage Building to Small Hotel Building: A Case Study of Bangkok Story Hostel, Asian Social Science, Vol. 14, No. 1, 2018, pp. 79-94, doi:10.5539/ass.v14n1p79

[13] Daniel P, Agnieszka G, Bolesław G, Piotr O, Barbara W, Soňa J, Julita M-P \& Mariusz S, The factors influencing the decision on the location of hotels depending on their size in Poland, Marketing and Trade, Vol. 2, 2017, pp. 213-223, doi:10.15240/tul/001/2017-2016

[14] Elena D, Natalia Z, Anna L, Maria P. \& Vladimir C, Methodological Aspects of Strategic Management of Financial Risks during Construction of Hotel Business Objects, Asian Social Science, Vol. 11, No. 20, 2015, pp. 229-234, doi.org/10.5539/ass.v11n20p229

[15] Ricardo A \& Vicente G, Production model for construction: theoretical framework, Buildings, No. 5, 2015, pp. 209-228; doi:10.3390/buildings5010209ISSN 2075-5309

[16] Eric Bonabeau. Agent-based modeling: Methods and techniques for simulating human systems, PNAS May 14, 2002. Vol. 99, suppl 3, pp. 7280-7287, doi.org/10.1073/pnas.082080899, available online: http://www.pnas.org/content/pnas/99/suppl_3/7280.full.pdf

[17] Anil B \& Mohammad N (2015), Innovation in hospitality and tourism industries, Journal of Hospitality and Tourism Technology, Vol 6, Issue: 3, available online: http://doi.org/10.1108/JHTT-08-20150033

[18] Yu. G. Lyisenko et al. (2004) Ekonomicheskaya kibernetika [Economic cybernetics], Donetsk, 516 p., in Ukraine

[19] Shchepak V (2017), Land monitoring: modeling and evaluation, Monograph 2, Association 1901 "SEPIKE” Innovation in Education and Economy, Norderstedt, Deutschland Poitiers, France, pp. 143-153, available online: http://docs.wixstatic.com/ugd/b199e2_0cf50f4bfaf441db8f56a1789 355bf42.pdf. 